The

Internationalization

of the Renminbi

Ronald W Anderson

SRC Special Paper No 11

January 2016

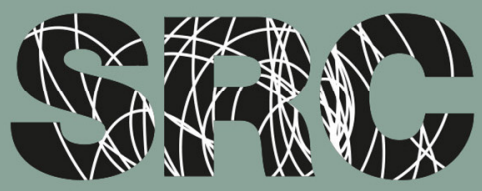

Systemic Risk Centre 
This paper is published as part of the Systemic Risk Centre's Special Paper Series. The support of the Economic and Social Research Council (ESRC) in funding the SRC is gratefully acknowledged [grant number ES/K002309/1].

Ronald W Anderson, Systemic Risk Centre and Financial Markets Group, London School of Economics and Political Science; CEPR

Published by Systemic Risk Centre

The London School of Economics and Political Science

Houghton Street

London WC2A 2AE

All rights reserved. No part of this publication may be reproduced, stored in a retrieval system or transmitted in any form or by any means without the prior permission in writing of the publisher nor be issued to the public or circulated in any form other than that in which it is published.

Requests for permission to reproduce any article or part of the Working Paper should be sent to the editor at the above address.

(C) Ronald W Anderson submitted 2015 


\title{
The Internationalization of the Renminbi ${ }^{*}$
}

\section{By Ronald W Anderson ${ }^{\dagger}$}

\author{
November 20, 2015
}

My subject is the internationalization of the Renminbi (RMB). While the development of the use of the Chinese currency in international trade and finance has been on-going for many years, the topic is very timely. The IMF is currently considering whether the RMB should join the elite club of major currencies that make up its reserve unit called the Special Drawing Rights (SDR), and a decision is expected by the end of this year.

China had proposed the RMB for SDR inclusion five years ago when the IMF last considered the composition of the SDR basket, and at that time it was unsuccessful. In 2015 the IMF once again considers the issue, and this year China has been very active in promoting its case. Understanding why the RMB was not accepted into the SDR basket in 2010 and what steps China has been taking in order to make its case convincing can tell us much about where China stands in the process of liberalizing its economy. It can also give us an insight into the major challenges China's policy makers will face in the years to come.

But first, what is an SDR? SDR's are not themselves freely exchanged, and you and I will never own one. Rather they are reserve assets for countries that are members of the IMF. They can be converted into the currencies in the basket and then into any currency that they wish on the open market. If a member draws against its account one SDR it will receive 0.632 USD, 0.41 EUR, 18.4 JPY and $0.0903 \mathrm{GBP}$. It can then convert these into any particular currency it needs at the current exchange rates. The fact that countries need to be able convert their SDR's into other currencies suggests the guiding principle that the IMF uses in deciding the composition of the SDR, namely, that the basket should be stable relative to major currencies. Stated otherwise, it should represent a relatively stable store of value and therefore be acceptable as a reserve currency. The IMF's operational criteria for SDR inclusion are that the currency should be that of a significant exporter and that the currency should be "freely usable" in trade and for balance of payments settlement by being traded on major exchanges. China has been the world's biggest exporting nation for some time; so it clearly meets the first criterion. But it was the hurdle of being "freely usable" that the RMB failed to clear in 2010.

Countries draw upon or repay their SDR accounts at the IMF infrequently and the amounts of currency involved are relatively minor compared to the huge size of the global foreign exchange market. So it is hard to point at any immediate practical benefit that China would enjoy if the RMB enters the SDR basket. Why then has China pushed so hard for SDR inclusion?

\footnotetext{
** The paper is based on talks given at the Guangdong University of Foreign Affairs and Xinhua College, Sun-Yat Sen University on November 4 and 11, 2015. I thank these institutions for the kind hospitality shown me during my stay in Guangzhou.

' Systemic Risk Centre and Financial Markets Group, London School of Economics; CEPR. r.w.anderson@lse.ac.uk The support of the Economic and Social Research Council (ESRC) in funding the SRC is gratefully acknowledged [grant number ES/K002309/1]
} 
One answer is that it is a matter of prestige. Inclusion of the RMB in the SDR basket would represent a highly public affirmation that China has joined the small group of nations who can claim to have a significant voice in deciding matters of global governance of economic policy. It implicitly would be a vote of confidence by world leaders that China is a reliable partner and that it can be counted upon to contribute to economic policies that will foster economic growth and financial stability.

However, China has other reasons for pushing for SDR basket inclusion that are motivated by Chinese domestic considerations and, in my view, these may be even more important than the external validation of its policies by world leaders. By setting the goal of SDR inclusion at this time, it helps to give momentum to the process of financial liberalization and gives concrete objectives to the leaders of the state bodies and major financial enterprises that collectively decide the structure of the Chinese financial system. In order to meet the IMF's criterion that the RMB be "freely usable" the Chinese authorities need to make RMB easily exchanged by domestic and foreign users. To achieve this, China will need to take important steps toward opening up capital flows into and out of the country. In 2009, Chinese leaders announced the goal of making Shanghai by 2020 an international financial centre that can rival London, New York and Tokyo. Today China is very far from matching those financial centres either in the degree of its openness of capital flows or in the maturity of its financial intermediaries, markets and regulatory authorities. The institutional changes that the IMF is looking for in evaluating whether the RMB should be included in the SDR basket are all steps that will also help convince market participants they can do serious finance in Shanghai and do so safely and efficiently.

China began its transition from a closed, centrally controlled economy toward an open, market based system in the 1980's. This is reflected in Figure 1 which shows China's exports expressed as a per cent of China's GDP.

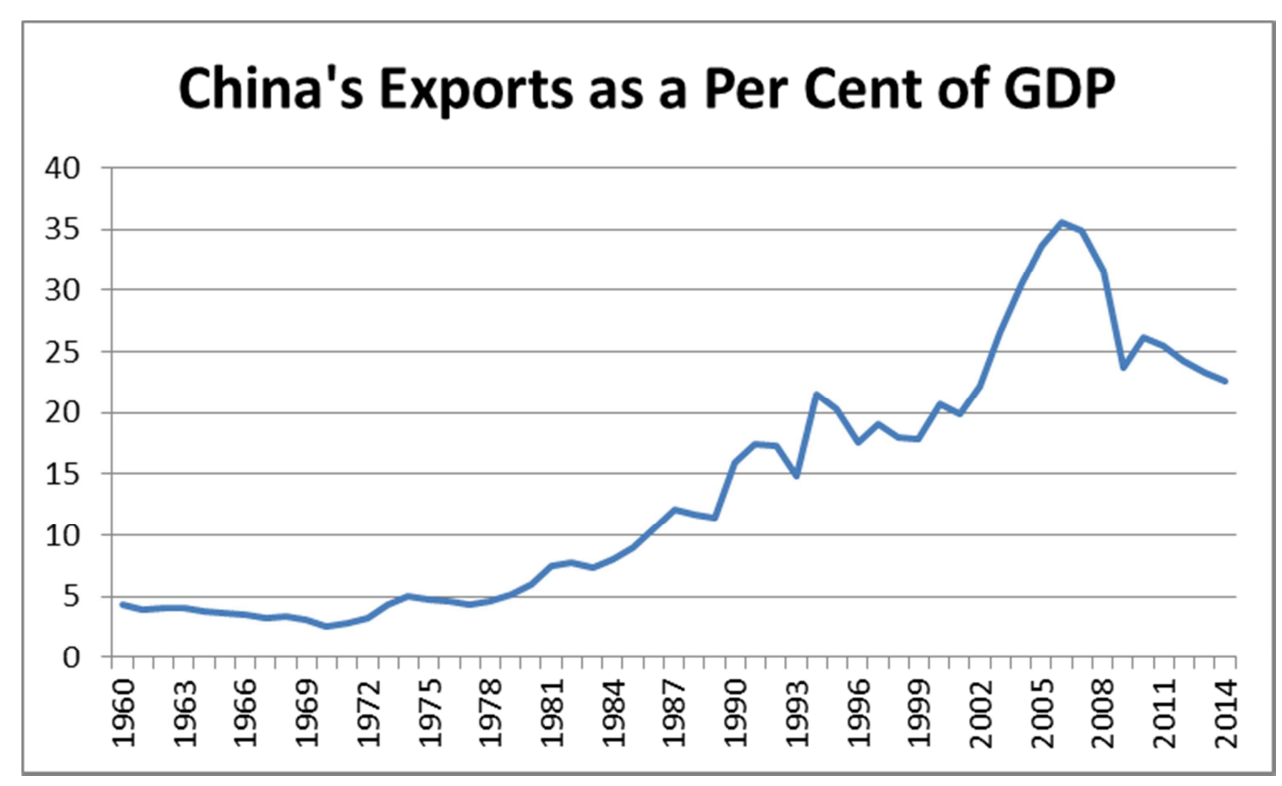

Figure 1: China's exports since 1960

Source: World Bank Economic Indicators 
This shows that starting in the early 1980's and continuing for 25 years the growth of China's exports outstripped that of its fast-growing GDP. That is, China pursued a policy of "export-led growth". This policy encountered headwinds in the mid-1990's when exports plateaued at something less than 20 per cent of GDP. But it was given new impetus with China's inclusion in the WTO in 2001, and this led to the burst of export growth until 2006 when its exports stood at 35 per cent of GDP. This remarkable performance was made possible only through a radical adaptation of Chinese stateowned and private manufacturing firms to meet the requirements of competing in world markets. Thus trade liberalization was the vector of change which has completely transformed the functioning of enterprises, has led to the migration of large segments of China's enormous population from the countryside to the urban manufacturing centres, and has led to a dramatic increase in the standard of living for many hundreds of millions of Chinese.

The pursuit of exports is a strategy that has been pursued by other Asian economies which have emulated in some degree the experience of Japan after the Second World War. However, unlike Korea, Indonesia, Malaysia and Thailand which opened their economies to trade and also to capital investments, China has moved cautiously in capital accounts liberalization. This caution paid off in the 1997 when the Asian financial crisis erupted and led to severe disruptions of those fastliberalizers but not to China.

That experience no doubt reinforced China's cautious tendencies, and until today it has maintained tight controls on both inflows and outflows of capital either as direct investments or as portfolio investments. These controls have given Chinese authorities a number of policy levers that it has actively used in trying to keep the Chinese economy on a strong growth path while trying to avoid overheating that could lead to destabilizing inflation. However, quantitative capital controls have the effect of creating a divergence between the domestic price of financial assets and the external price of comparable assets. And these distortions represent an important source of economic inefficiency by making the domestic cost of capital significantly different than the cost of capital in world markets. For example, according to Deutsche Bank research in 2014 the domestic interest rate set by the Peoples' Bank of China for good borrowers stood at 6.4 per cent while at the same time the off-shore rate on BBB RMB paper in Hong Kong was 3.95 per cent. This meant that some Chinese enterprises with good projects returning 4 or more per cent were being starved for capital and were unable to grow or were forced to shut down.

The distortions created by capital controls are also reflected in the divergence of on-shore and offshore RMB exchange rates. This has become clear in recent years with the emergence of an active market for off-shore RMB in HK. At times the off-shore rate against dollars, denoted CNH/USD, has differed significantly from the Chinese domestic rate, denoted CNY/USD. And this has led participants to pursue a variety of wasteful strategies of dubious legality in an attempt arbitrage the difference.

In light of the difficulty of maintaining complicated exchange controls in an economic system that is so deeply engaged in competing in world trade, starting in 2009 Chinese authorities began to make significant steps to relax capital controls. This has involved a number of technical institutional changes which have laid the foundation for the freer flow of capital. An example of this has been the cooperation for cross-border RMB trade settlement between the PBOC and the monetary 
authorities in Hong Kong, Macao, and ASEAN countries. This operated at first for exporting firms based in Shanghai and four cities in the Pearl River Delta region of Guangdong Province, but it was progressively extended to exporters in the rest of China. A further important change was the creation of a mechanism for outward bound direct investments by Chinese enterprises. Inward bound stock market investments in China have been authorized for the last ten years under the Qualified Foreign Investment Institution (QFII) scheme, but the quotas been increased significantly in recent years. At the same time a significant number of Chinese companies have been listed on the Hong Kong Stock Exchange. The first major step toward outward bound portfolio investment was taken in 2014 with the initiation of the Shanghai-Hong Kong Stock Connect programme. Given strong interest by mainland investors, the quota under this programme was quickly reached and has been increased subsequently. In response to this new source of equity investors, financial intermediaries have issued RMB denominated exchange traded funds (ETF's). This opens the door for Chinese investors to invest in RMB assets that track the performance of a variety of foreign market segments.

The steps toward opening investment flows to and from China have continued at an even more rapid pace in 2015 as part of China's efforts to gain SDR inclusion for the RMB. Foreign central banks, sovereign wealth funds and international financial institutions have been granted access to issuing on-shore RMB bonds. The fixing procedure for the CNY has been modified to be more in line with that of the $\mathrm{CNH}$ thus removing one impediment to $\mathrm{CNY}-\mathrm{CNH}$ convergence. President $\mathrm{Xi}$ Jinping's visit to the UK gave rise to a flurry of bilateral measures between the China and the UK including the issuance of a RMB denominated bond issue by the UK Treasury, establishment of a channel for RMB trade settlement in London, and the issuance in London of short-term RMB denominated paper by the People's Bank of China. In part, this has been directed at making London the most important centre for trading RMB assets that operates in the prime time-zone that straddles both Asian trading and North American trading.

Taken as a whole these steps represent a substantial move toward more open financial markets that are freed up from the heavy constraints imposed previously. This will give Chinese firms alternative sources of capital funds. Liberalization also promises to deliver substantial benefits to Chinese investors who will have the opportunity to diversify their holdings with foreign investments. It also means that domestic financial markets will be transformed through the participation of foreign financial institutions. Opening an economy to foreign portfolio flows is sometimes feared because the so-called "hot money" from abroad might lead to high stock market volatility. However, in the Chinese context where the notoriously skittish behaviour of domestic traders can generate enormous volatility, the presence of foreign institutional traders, some of which will be operating unlevered, slow-moving index-tracking funds, could serve to reduce the of volatility of the Shanghai and Shenzhen stock markets.

The opening of Chinese financial markets will not only bring benefits. It also will bring very significant challenges for Chinese policy makers. In fact, these challenges have become increasingly apparent since 2014 .

As has already been argued, the main thrust of Chinese economic policy can be understood as export-led growth. This policy encountered difficulties starting in 2008 with the onset of the World Financial Crisis which induced a downturn in the global economy. While Chinese exports rebounded 
with the return to growth of global GDP, in fact, the pace of export growth lagged behind the growth of the rest of the Chinese economy. This is apparent in Figure 1 which shows that the ratio of exports to GDP has fallen sharply since 2007. The reasons for the relative weakness in Chinese exports can be found in the steady increase in Chinese domestic labour costs and in the appreciation of the RMB relative to the USD and other major currencies. The latter is reflected in Figure 2 which plots the course of the CNY/EUR exchange rate since 2007 and 2015. During this period the RMB has undergone a very large and sustained appreciation. Between early 2014 and early 2015 alone it appreciated 25 per cent, falling from about 8.7 CNY/EUR to about 6.6 CNY/EUR.

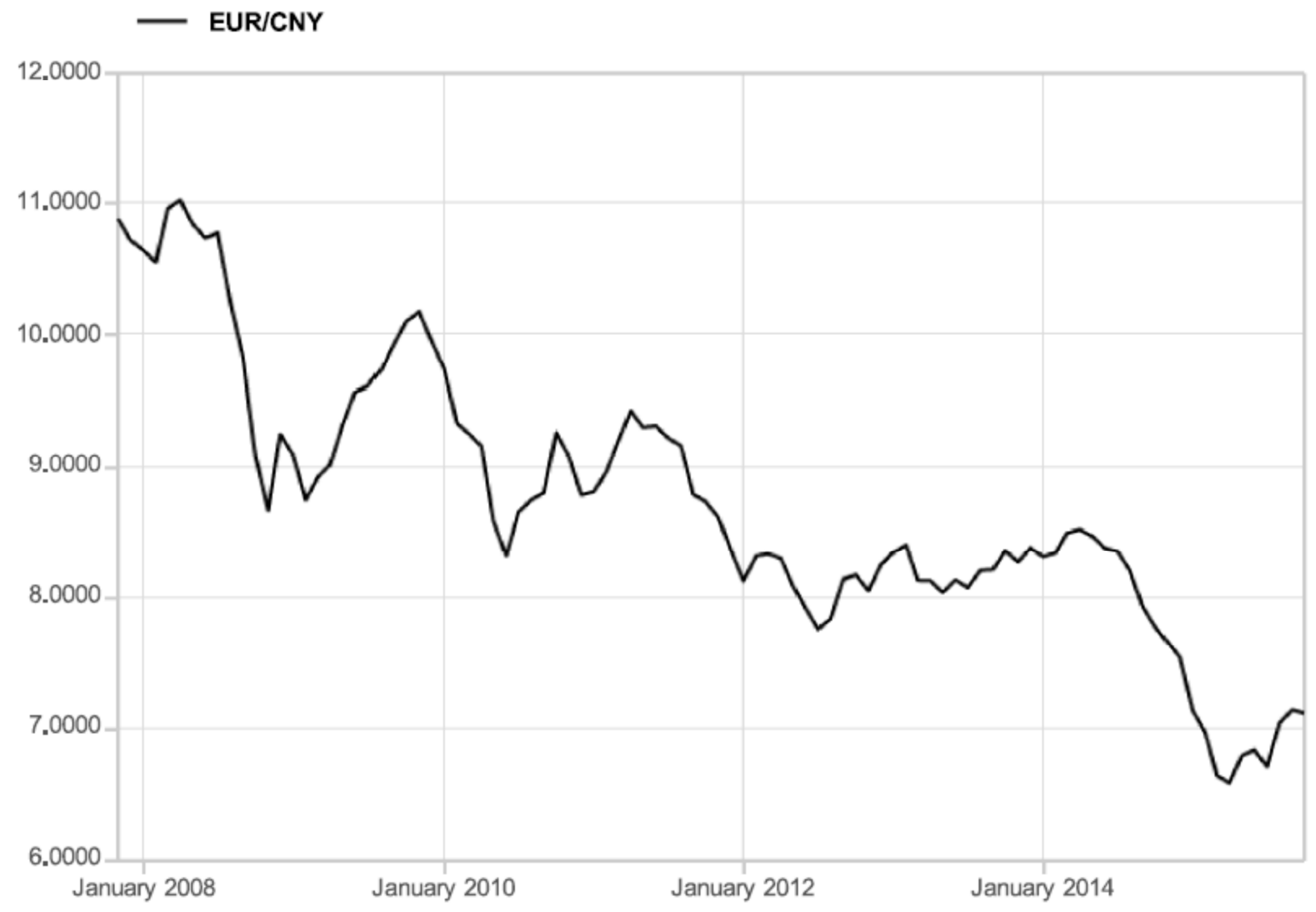

Figure 2: The RMB Euro Exchange Rate

The weak relative performance of the Chinese export sector combined with a sustained appreciation of the RMB on world currency markets suggests that China is in a transition phase that will gradually lead it to abandon its reliance on exports as the main engine of economic growth and will increasingly focus on the development of the internal market. In the future, China will probably begin to resemble somewhat the profile the US which is major player in world trade but where, given the huge size of the internal market, exports represent only about 13 per cent of GDP.

This important evolution in China's trade position has profound implications for its financial sector and for the conduct of monetary policy. The policy of export led growth was supported by a complementary exchange rate policy which resulted in the undervaluation of the RMB relative to the so-called purchasing power parity exchange rate. In order to prevent the appreciation of the RMB or at least to slow it, Chinese authorities needed to intervene regularly on foreign exchange markets to 
supply RMB in order to fill the gap between RMB demand and supply. This resulted in the accumulation of large amounts of foreign reserves. This is seen Figure 3 which shows that official reserves grew enormously since China's entry in the WTO in 2001, reaching a total of about 4 trillion USD in August 2014. A large fraction of these reserves have been kept in USD largely in the form of US Treasury Securities. By way of comparison, the total debt of the US Federal Government is about 18 trillion USD. So China is one of the US's largest creditors.

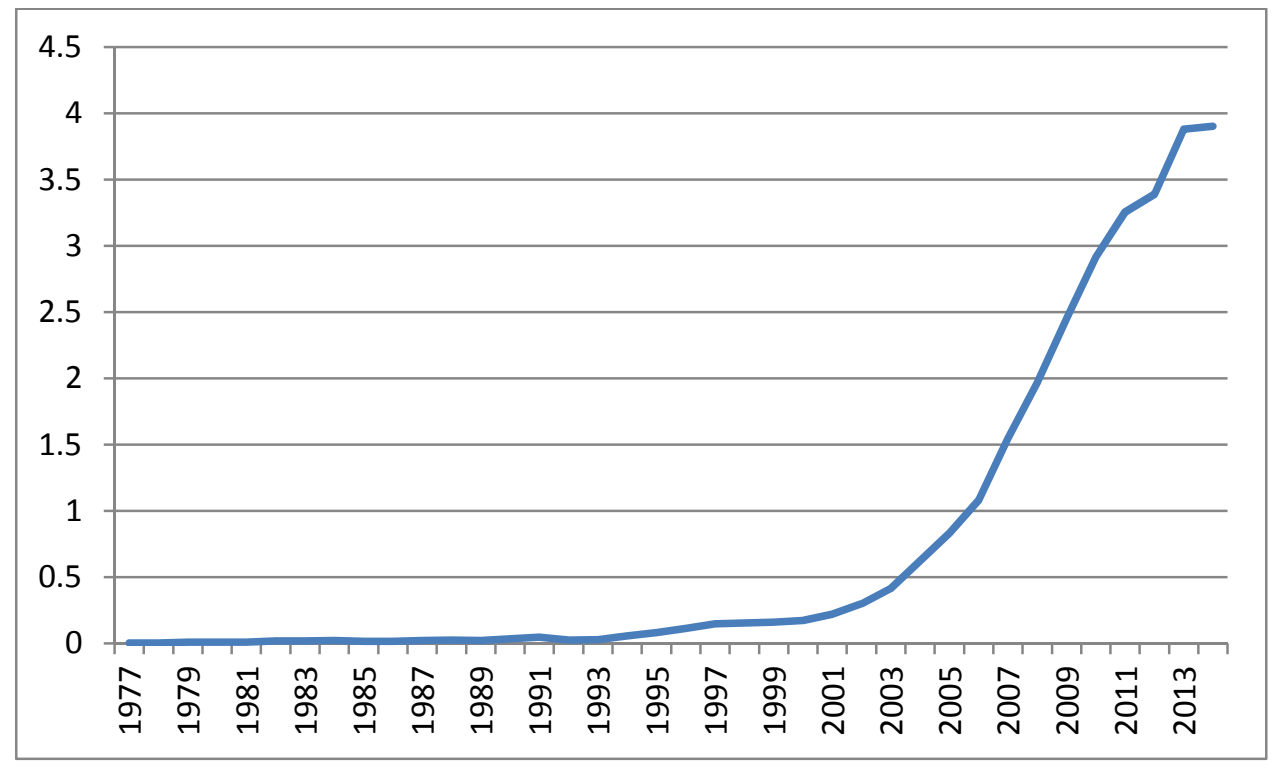

Figure 3: China's Foreign Reserves (trillion USD)

Source: World Bank Economic Indicators

In the past, the fact that private demand for RMB regularly exceeded private supply of RMB on world markets meant that it was relatively easy for Chinese authorities to maintain a reasonably stable exchange rate or to allow it to change smoothly along a trend. They merely needed to increase or decrease its RMB sales to compensate for short-term fluctuations of supply and demand at the target exchange rate.

There are reasons to believe that this pattern has changed in the last year and that the RMB had reached the point earlier in 2015 where RMB demand and supply for trade purposes were roughly balanced. In addition, since 2014 the weakness of Chinese exports has convinced domestic and foreign investors that the traditionally strong growth sectors of the Chinese economy no longer represent attractive investment prospects. The result has been a shift from private capital inflows to private capital outflows. This has meant that the overall balance of supply and demand on foreign exchange markets switched from excess demand for RMB to excess supply. This implied that in order to continue their policy of exchange rate stabilization Chinese authorities had to intervene on markets by buying RMB and that to do so they had to draw down their total reserves by approximately 500 billion USD. Such a steep decline in reserves led China to re-evaluate its foreign exchange policy, and in August it announced major changes with the effect that it would tolerate larger fluctuations in the exchange rate than in the past. The RMB was allowed to fall some 4 per cent in USD terms, but even that depreciation was insufficient to balance the market. Chinese reserves dropped by 93 billion USD in the month of August alone. World stock markets reacted to the August currency announcement with a broad sell-off. In the following weeks the world financial 
press was filled with discussions about the weakness of the Chinese economy with wild speculations about the way Chinese authorities would respond. This was an unprecedented example of a Chinese policy announcement having a significant impact on world markets. American and European firms in general are not very heavily dependent on China related business. So it unlikely that stock market participants feared a direct impact on those firms' earnings. Rather the reaction of Western stock markets seemed to reflect a perception of increased risk because of the uncertainty in the policy direction that China might take in responding to its current growth slow-down.

To conclude, I have argued that by proposing that the RMB be included in the SDR China has staked its claim to have a full voice in the global governance of economic policy making. This is a manifestation of China's growing self-confidence based on its success in sustaining rapid development of its economy for more than two decades despite many doubters of its policies worldwide. The leadership role played by the China in the creation of the Asian Infrastructure Investment Bank is another important example of this direction of Chinese international policy. In order to assume this new role China has had to go beyond its ingrained caution regarding the opening of capital flows and is moving decisively in the direction of a more liberalized financial sector. This holds the promise of a more flexible means of financing further economic growth in China and in providing an aging population a means of assuring the continued increase in economic well-being in the future. But this carries with it very important challenges for China in framing policies that are appropriate for a new phase in China's development which will be based on the growth of its internal market. One challenge is to move away from quantitative controls of financial flows toward monetary policy tools that are more compatible with an open, market-based financial system. However, just as important, Chinese authorities need to be able to communicate the logic of their policies to the international policy community, to world markets, and, most importantly, to the Chinese people themselves. 
The London School of Economics and Political Science Houghton Street London WC2A 2AE United Kingdom

Tel: +44 (0)20 74057686 systemicrisk.ac.uk 